\title{
The Use of Plastic Fiber for Minimizing Stripping Potential of Bituminous Mixture
}

\author{
Nura Usman ${ }^{1 *}$, Mohd Idrus Mohd Masirin ${ }^{2}$, Kabiru Abdullahi Ahmad ${ }^{3}$, \\ Muhammad Nda ${ }^{4}$
}

\author{
${ }^{1}$ Department of Civil Engineering, Hassan Usman Katsina Polytechnic, PMB 20152 Katsina Nigeria. \\ ${ }^{2}$ Faculty of Civil and Environmental Engineering, Universiti Tun Hussein Onn Malaysia, 86400 Parit Raja, Malaysia. \\ ${ }^{3}$ Department of Civil Engineering, Bayero University Kano, Nigeria. \\ ${ }^{4}$ Department of Civil Engineering, Federal Polytechnic Bida, Niger State, Nigeria.
}

Received 19 March 2018; accepted 11 December 2018, available online 31 December 2018

\begin{abstract}
One of the effects of water in bituminous pavement is the stripping of aggregates from the mixture causing severe distresses such as potholes. In this study, fiber was produced using recycle plastics and it was used as reinforcement in bituminous mixture against moisture damage. The reinforcements were $0.3 \%, 0.5 \% 0.7 \%$ and $1.0 \%$ of the total weight of bituminous mixture with a view to determine the effective fiber dosage. The stripping potential of control and fiber reinforced mixtures were determined using moisture susceptibility test. From the test results, highest tensile strength ratio (TSR) was obtained in mixtures containing $0.5 \%$ recycle plastic fiber. The result also indicated higher indirect tensile strength for both dry and saturated at $0.5 \%$ plastic fiber reinforcement. For $0.7 \%$ and $1.0 \%$ recycle plastic fiber reinforced bituminous mixture, both tensile strength and tensile strength ratio were low compared to that of control mixture. From this study, reinforcing bituminous mixture using $0.5 \%$ recycle plastic proved to be effective in improving stripping resistance.
\end{abstract}

Keywords: Stripping, moisture damage, recycle plastic, fiber, reinforcement, bituminous mixture

\section{Introduction}

Bituminous mixture is the most currently used material for surfacing of road known as flexible pavements. When water penetrates into flexible pavement, it tends to undermine the pavement strength by weakening the bond between aggregates and bitumen causing stripping. Stripping is among the major source of distress on flexible pavement especially in the high rainfall regions. When moisture damage is occurred, the mechanical properties of bituminous pavement are altered and gradually other failures such as shoving, rutting and cracking may occur [1]. Water in midst of asphalt concrete do results in adhesion failure at aggregate-binder interface, it also distract the cohesion within filler-binder mastic [2].

Water tend to diffuses in to the pavement across bitumen films and affect the partially coated aggregates. The resulted moisture damage may occur as mechanisms such as pore pressure, hydraulic scour, spontaneous emulsification, displacement and detachment [3]. Although traffic loading, moisture and other environmental factors are blamed to be responsible for moisture damage, the quality of paving mixture is also a determinant of the failure [4].

In asphalt concrete technology, moisture susceptibility is determined using Tensile Strength Ratio
(TSR). Dry and Saturated tensile strengths of mixtures are determined and the ratio of saturated tensile strength to dry tensile strength is expressed in percentage as TSR value. A minimum value of $80 \%$ is considered acceptable.

To minimize the effect of water in flexible pavement, researchers and engineers introduced the use of fiber. Herraiz [5] investigated the use of polyester, hemp and posidonia oceanica fibers in strength improvement of bituminous mixture, he concluded that addition of fiber have improved the moisture susceptibility of the bituminous mixes. Anurag et al. [6] used waste polyester fiber to improve the indirect tensile strength of bituminous mixes. Their result indicated an improvement of water damage resistance in the polyester reinforced mixes. Xue and Qian [7] evaluated the performance of mineral fiber in epoxy asphalt concrete. They concluded that in addition to improved reveling resistance and low temperature cracking, mineral fiber has improved moisture damage resistance by $98 \%$. From literature most of the fibers used in reinforcement of bituminous mixture are synthetic fibers, therefore there is the need to use recycle fiber.

On the other hand, global plastic waste generation is at high rate. A report by Plasticseurope [8] for 2014/2015 affirms that about 299 million tons of plastic was produced in 2013 globally, out of which 59 million tons 
were produced and mostly used in Europe. However, due to high technology and relatively good environmental regulations in Europe, about $62 \%$ of plastic waste generated goes to either recycling or used for energy recovery leaving only $38 \%$ for landfills [8].

Meanwhile, unlike in Europe World Bank review on global solid waste [9] reports that, more than $80 \%$ of solid waste produced in low and middle income countries end up in landfills [9]. The percentage of plastic in the solid waste is $20-30 \%$ by volume [10]. Additionally, $60 \%$ of plastics in municipal waste are Polyethylene Terephthalate (PET) bottles[11]. Therefore, it is necessary to develop a simple means of recycling this waste[12].

To improve the performance of asphalt mixture against moisture damage and to reduce plastic waste, recycled PET bottles were used to produce PET fiber that was incorporated into asphalt concrete mixtures.

\section{Materials}

The materials used are aggregates, bitumen and recycle plastic fiber. Quality test was performed on the materials, the results are presented in tables 1, 2 and 3 for bitumen, aggregates and plastic fiber respectively. Using maximum aggregates size (NMAS) of $12.5 \mathrm{~mm}$, the asphalt mixture was designed based on Superpave system. The volumetric property of the designed mixture is presented in Table 4. The waste plastic bottle used for the production of plastic fiber was made from Polyethylene terephthalate (PET). PET is a ubiquitous thermoplastic polymer used for daily household objects. Due to its significant water and moisture resistance, it is used soft drink bottles. It possesses shear strength and thermal resistance even if its subjected to $175^{\circ} \mathrm{C}[13]$. Fig. 1 shows a plastic fiber used in this study.

Table 1: Properties of bitumen used in this research

\begin{tabular}{cccc}
\hline Test & Method & Value & Specification \\
\hline Penetration $(\mathrm{dmm})$ & ASTM D5-97 & 83 & $80-100$ \\
Softening point $\left({ }^{\circ} \mathrm{C}\right)$ & ASTM D36 & 43 & $45-52$ \\
Flash point $\left({ }^{\circ} \mathrm{C}\right)$ & ASTM D92-5 & 259 & Min 232 \\
Ductility $(\mathrm{cm})$ & ASTM D113-99 & $>100$ & Min 100 \\
\hline
\end{tabular}

Table 2: Properties of aggregates used in this research

\begin{tabular}{|c|c|c|c|}
\hline Property & Method & Value (\%) & Requirement (\%) \\
\hline Flakiness Index & BS-812-105-1 & 15 & $<20$ \\
\hline $\begin{array}{c}\text { Elongation Index } \\
\text { Aggregates Impact }\end{array}$ & BS-812-105-2 & 17 & $<20$ \\
\hline $\begin{array}{c}\text { Value } \\
\text { Aggregates Crushing }\end{array}$ & BS-812-112 & 21 & $<30$ \\
\hline $\begin{array}{l}\text { Value } \\
\text { Fine Aggregates }\end{array}$ & BS-812-110 & 21 & $<30$ \\
\hline Angularity & AASHTO T304 & 49.5 & Min 45 \\
\hline sand Equivalent & AASHTO T176 & 51.3 & MIN 45 \\
\hline
\end{tabular}

Table 3: Properties of recycle plastic fiber

\begin{tabular}{lcr}
\hline Property & Method & Value \\
\hline Tensile strength (MPa) & ASTM C1557 & 192.4 \\
Stiffness (N/m) & ASTM C1557 & 27693 \\
Young's Modulus (MPa) & ASTM C1557 & 3924.2 \\
Elongation at Break (\%) & ASTM C1557 & 34.2 \\
Water absorption (\%) & ASTM D570 & 0.2 \\
Specific gravity (g/cm3) & ASTM D792 & 1.356 \\
\hline
\end{tabular}


Table 4: Volumetric properties of designed mixture

\begin{tabular}{ccc} 
Property & Value (\%) & Criteria (\%) \\
\hline Air void & 4 & 4 \\
VMA & 16 & Minimum of 13 \\
VFA & 75 & $65-76$ \\
$\begin{array}{c}\text { Bitumen } \\
\text { content }\end{array}$ & 4.7 & $4-11$ \\
\hline
\end{tabular}

\section{Methods}

\subsection{Moisture Susceptibility Test}

Moisture susceptibility test was conducted on both control and recycle plastic fiber reinforced mixtures. The test method used was AASHTO T283[14] popularly known as modified Lottman test, the method uses tensile strength ratio (TSR) to evaluate moisture susceptibility of asphalt concrete mixture. The samples were produced at $7 \pm 0.5 \%$ air voids using the respective optimum bitumen contents of control and reinforced asphalt mixtures.

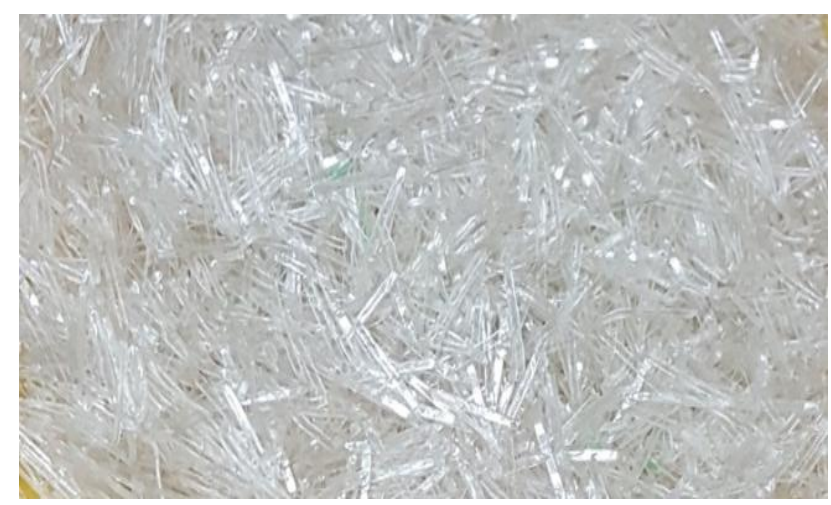

Fig. 1 Recycle plastic fiber

The dry sub set was tested after two hours curing at $25^{\circ} \mathrm{C}$. The wet sub set was saturated and cured in water at $60^{\circ} \mathrm{C}$ for 24 hours, then cured in water at $25^{\circ} \mathrm{C}$ and finally tested at $25^{\circ} \mathrm{C}$.

\subsection{Data Analysis}

Response surface methodology (RSM) was used for the data analysis in this studies, RSM is a new approach accepted for analysis in pavement engineering [4, 15-17]. RSM is a statistical tool used for predicting the relationship between factors and responses and also in the analysis of problems[18], it also provide a maximum process performance using designed experiments, historic data and polynomial equations[18].

Using Design Expert 7.0 software, recycle plastic fiber percentage and temperature were used as factors while dry indirect tensile strength (ITS dry), saturated tensile strength (ITS saturated) and tensile strength ratio
(TSR) were used as responses were analyzed at 15 runs using historic data as shown in Table 5. To estimate the response variable, a Montgomery quadratic polynomial

regression equation was used for four independent variables as shown in equation 1[18]. After the RSM analysis, pictorial surface plots and ANOVA were produced depicting the effect of temperature and percentage addition of plastic fiber on the bituminous mixtures.

$Y=b_{0}+\sum_{i=1}^{n} b_{i} x_{i}+\sum_{i=1}^{n} b_{i j} x_{i}^{2}+\sum_{i=1}^{n} \sum_{j=1}^{n} b_{i j} x_{i} x_{j}+\varepsilon$

In Eq. 1, $\mathrm{Y}$ is the response variable, $\mathrm{n}$ is the number of factors, $\varepsilon$ is random error, $b_{0}, b_{i}, b_{i i}$ and $b_{i j}$ are constant coefficients of intercept, linear, quadratic and interaction terms (independent variables] respectively.

\section{Results and Discussion}

Table 5 is RSM experimental design layout for historic data obtained from moisture susceptibility test.

Table 5: Experimental design layout and results for moisture susceptibility test

\begin{tabular}{|c|c|c|c|c|c|}
\hline \multirow[b]{2}{*}{$\begin{array}{l}\text { No of } \\
\text { Runs }\end{array}$} & \multicolumn{2}{|c|}{ Factors } & \multicolumn{3}{|c|}{ Responses } \\
\hline & $\begin{array}{c}\text { plastic } \\
\text { Fiber } \\
(\%) \\
\end{array}$ & $\begin{array}{c}\text { Temperature } \\
\text { (C) }\end{array}$ & $\begin{array}{c}\text { ITS } \\
\text { Dry } \\
(\mathrm{KPa}) \\
\end{array}$ & $\begin{array}{c}\text { ITS } \\
\text { Saturated } \\
(\mathrm{KPa}) \\
\end{array}$ & $\begin{array}{l}\text { TSR } \\
(\%) \\
\end{array}$ \\
\hline 1 & 0 & 24.98 & 105 & 93 & 88 \\
\hline 2 & 0 & 24.99 & 95 & 83 & 87 \\
\hline 3 & 0 & 25 & 93 & 75 & 80 \\
\hline 4 & 0.3 & 24.98 & 118 & 105 & 89 \\
\hline 5 & 0.3 & 24.99 & 111 & 95 & 85 \\
\hline 6 & 0.3 & 25 & 107 & 93 & 87 \\
\hline 7 & 0.5 & 24.98 & 134 & 121 & 90 \\
\hline 8 & 0.5 & 24.99 & 127 & 115 & 90 \\
\hline 9 & 0.5 & 25 & 121 & 105 & 87 \\
\hline 10 & 0.7 & 24.98 & 95 & 75 & 79 \\
\hline 11 & 0.7 & 24.99 & 93 & 73 & 78 \\
\hline 12 & 0.7 & 25 & 90 & 72 & 80 \\
\hline 13 & 1 & 24.98 & 76 & 56 & 74 \\
\hline 14 & 1 & 24.99 & 69 & 54 & 78 \\
\hline
\end{tabular}




\begin{tabular}{llllll}
15 & 1 & 25 & 68 & 45 & 66 \\
\hline
\end{tabular}

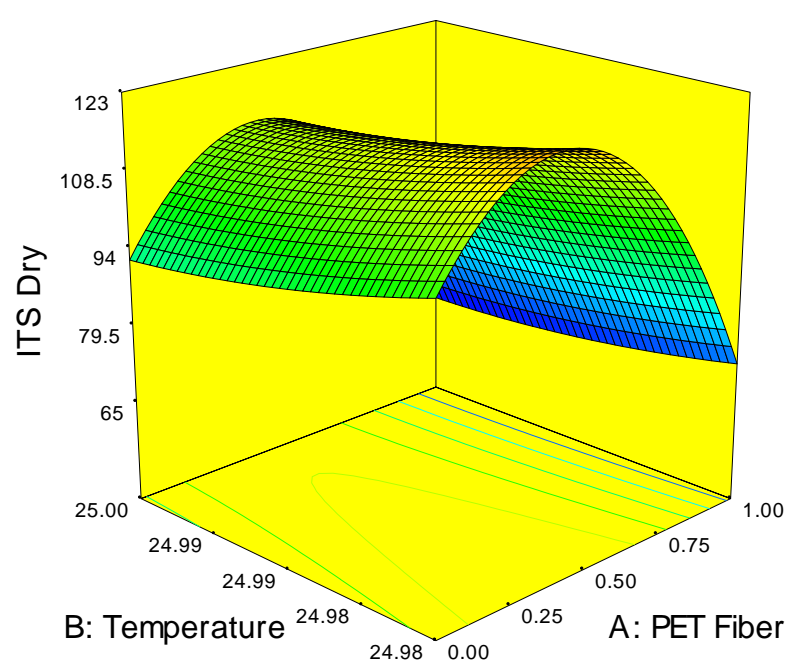

Fig. 2: Surface plot of dry indirect tensile strength versus Temperature and PET fiber percentage

Fig. 2 is a pictorial surface plot for dry sub-set's indirect tensile strength, the trend shows an increase in tensile strength for reinforced mixtures at $0.3 \%$ and $0.5 \%$ plastic fiber by $13 \%$ and $23 \%$ respectively compared to neat mixture but decreased at $0.7 \%$ by $4 \%$ and $1 \%$ by $27 \%$. This may be caused by excess plastic fiber that tends to replace aggregates.

Fig. 3 is a surface plot for conditioned samples (saturated), the tensile strength improvement was $14 \%$ at $0.3 \%$ and $26 \%$ at $0.5 \%$ fiber reinforcement. The improvement in the tensile strength of reinforced mixtures is guided by high tensile strength of recycle plastic fiber at the test temperature $\left(25^{\circ} \mathrm{C}\right)$. The stiffness and storage modulus of plastic fiber tends to restrain the reinforced mixture from responding to the applied tensile stress. The tensile strength of saturated sub set was reduced by $12 \%$ at $0.7 \%$ fiber reinforcement and reduced by $34.5 \%$ at $1.0 \%$ fiber reinforcement.

Fig. 4 is a pictorial surface representation of tensile strength ratio for neat and reinforced bituminous mixtures. From this figure, the TSR of all mixtures excluding $1.0 \%$ reinforced mixture have satisfied AASHTO T283 requirement of $\geq 80 \%$ TSR value[14]. In addition, the TSR values for $0.3 \%$ and $0.5 \%$ reinforced mixtures are higher than that of control mixture. This is attributed by very low water absorption of plastic fiber $(0.2 \%)$ and high storage modulus at $25^{\circ} \mathrm{C}$. This result is similar to the findings of research conducted on reinforced bituminous mixture with lignin, brucite, basalt and polyester by Xiong et al. [20].

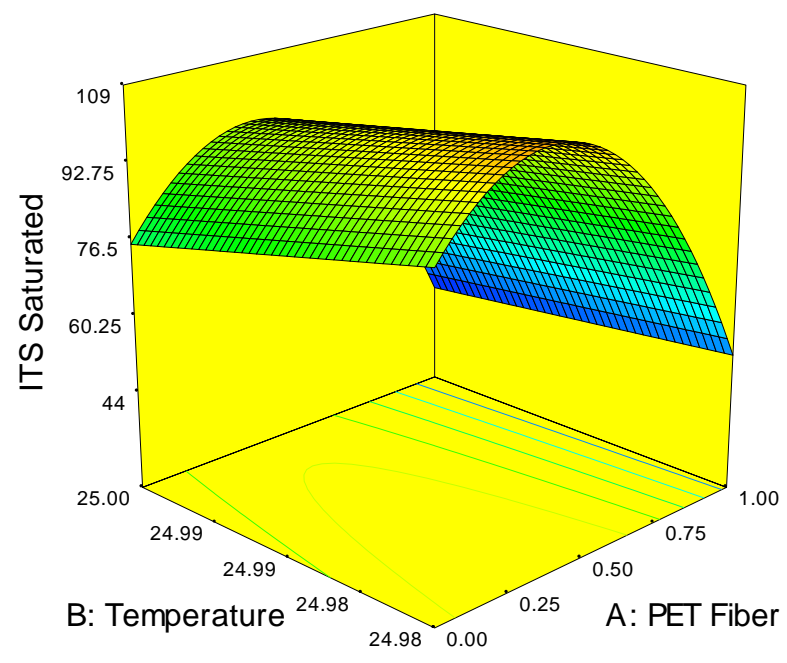

Fig. 3: Surface plot of saturated indirect tensile strength versus Temperature and plastic fiber percentage

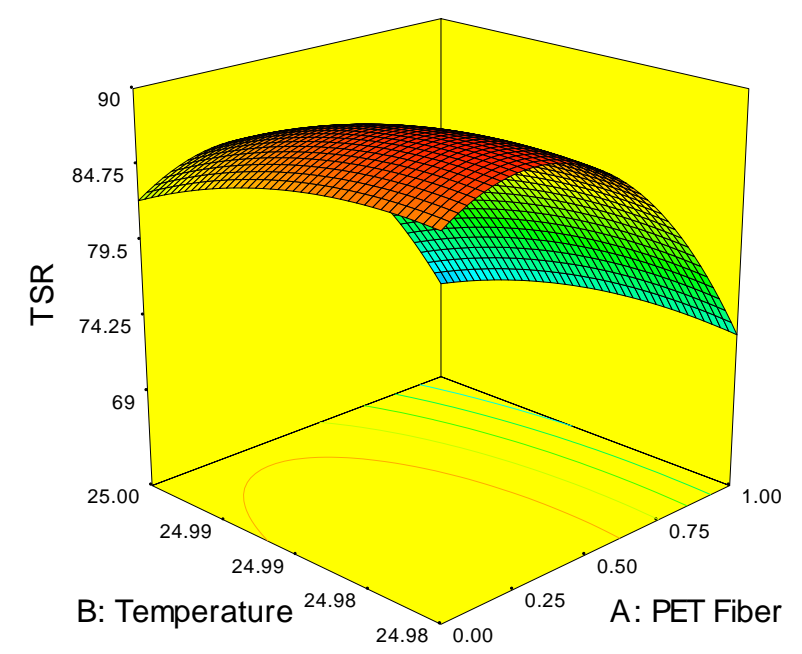

Fig. 4: Surface plot of tensile strength ratio versus Temperature and plastic fiber percentage

$$
\begin{aligned}
& \text { ITS Dry }=113.71-14.83 A-4.9 B+1.38 A B- \\
& 31.7 A^{2}+1.7 B^{2}
\end{aligned}
$$

ITS Saturated $=99.32-17.99 A-6 B+2.28 A B-$ $33.02 A^{2}+0 B^{2}$

$T S R=87.05-6.7 A-2.0 B+0.26 A B-7.44 A^{2}-$ $1.6 B^{2}$

Equations 2, 3 and 4 are the models generated by RSM for ITS dry, ITS saturated and TSR respectively. Analysis of variance was conducted to check the validity of these models and data statistically, the result is summarized in Table 6. 
Table 6: ANOVA analysis for moisture susceptibility test result

\begin{tabular}{|c|c|c|c|c|}
\hline Parameter & $\begin{array}{l}\text { ITS } \\
\text { Dry }\end{array}$ & $\begin{array}{l}\text { ITS } \\
\text { Sat }\end{array}$ & TSR & Remarks \\
\hline $\begin{array}{l}\text { Model p- } \\
\text { value }\end{array}$ & 0.0024 & 0.0039 & 0.0007 & Significant \\
\hline $\begin{array}{l}\text { Model f- } \\
\text { value }\end{array}$ & 9.18 & 8.1 & 6.76 & Significant \\
\hline $\mathrm{R}^{2}$ & 83.6 & 81.7 & 79 & Significant \\
\hline $\mathrm{R}^{2}$ Adjusted & 74.5 & 71.6 & 67 & $\begin{array}{l}\text { In agreement } \\
\text { with } \\
\text { predicted } \mathrm{R}^{2}\end{array}$ \\
\hline $\mathrm{R}^{2}$ Predicted & 66 & 63 & 59 & $\begin{array}{c}\text { In agreement } \\
\text { with adjusted } \\
\mathrm{R}^{2}\end{array}$ \\
\hline $\begin{array}{l}\text { Adequate } \\
\text { Precission }\end{array}$ & 8.8 & 8.4 & 7.8 & $\begin{array}{c}\text { Adequate } \\
\text { signal }\end{array}$ \\
\hline
\end{tabular}

From Table 6, the p-values for all the results are significant, and also the model f-values are significant. The coefficients $\mathrm{R}^{2}$ are also significant at $95 \%$ confidence level, $\mathrm{R}^{2}$ predicted and $\mathrm{R}^{2}$ adjusted have all agreed to each other hence the analysis is acceptable. The precisions of the generated models are all adequate as are all above the minimum requirement of 4 .

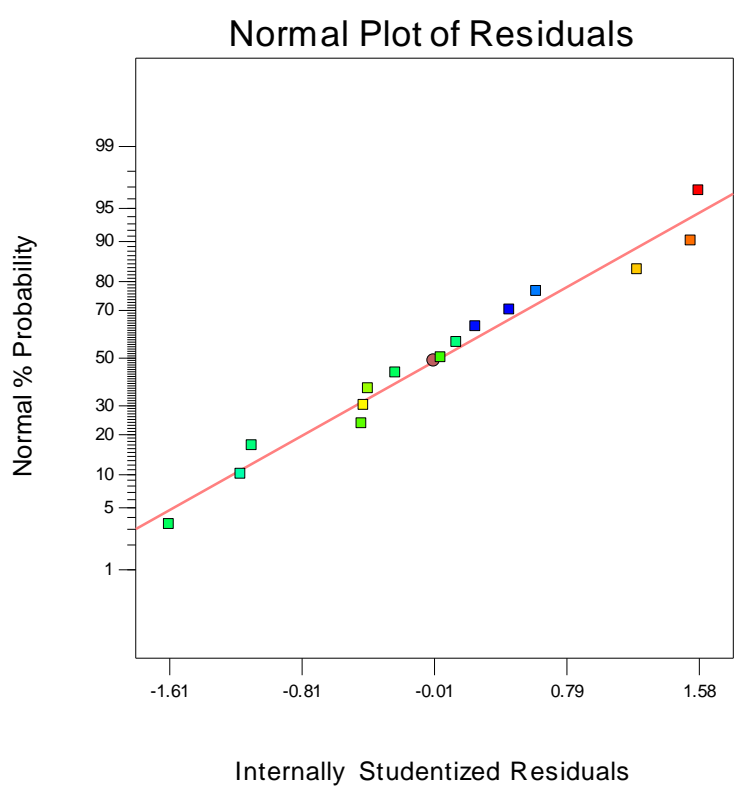

Fig. 5: Normality plot for indirect tensile strength of dry sub set data

Fig. 5, 6 and 7 are the normality plots for ITS dry, ITS saturated and TSR respectively. The plots show that all the data are located around the graphs' line which is a clear indication of the normality of data.

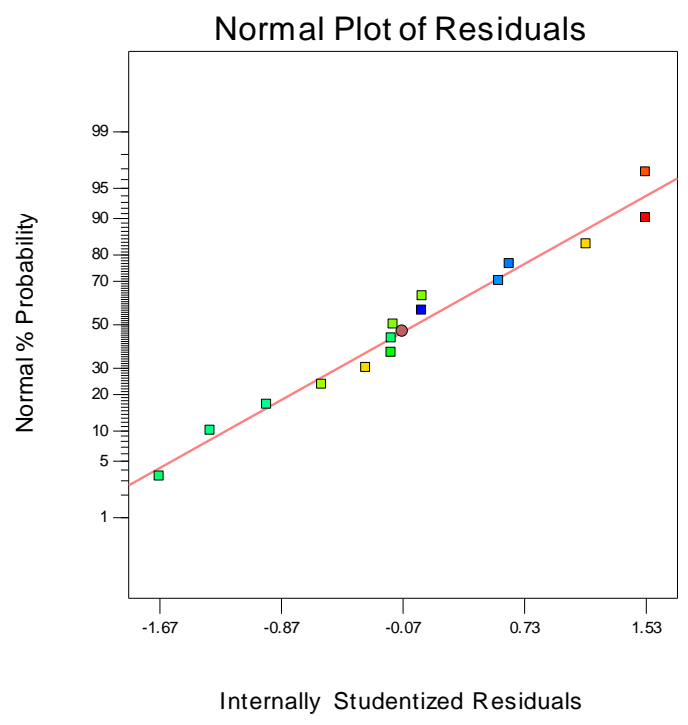

Fig. 6: Normality plot for indirect tensile strength of saturated sub set data

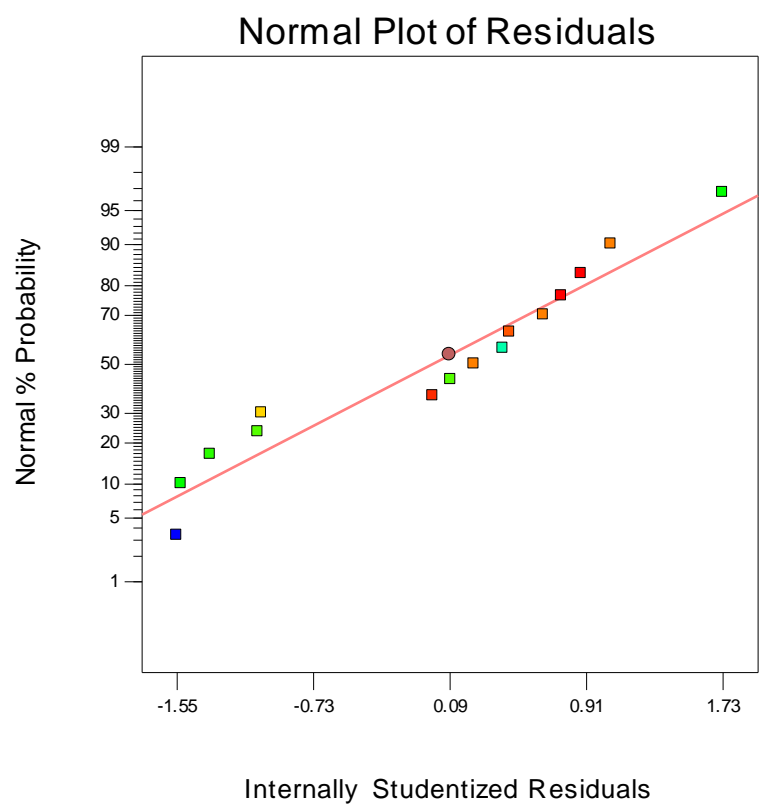

Fig. 7: Normality plot for tensile strength ratio (TSR) data

\section{Conclusion}

The stripping/moisture damage resistance of control and recycle plastic fiber reinforced mixtures was evaluated using moisture susceptibility test. The result indicated highest TSR value in mixtures containing $0.5 \%$ recycle plastic fiber followed by mixtures containing $0.3 \%$ compared to control mixture. Further addition of recycle plastic fiber at 0.7 and $1.0 \%$ yielded decrease in dry ITS, saturated ITS and TSR values. Therefore, it is concluded that $0.5 \%$ addition of recycle plastic fiber is the optimum dosage for moisture damage resistance in bituminous mixture. 


\section{References}

[1] Khodaii A, Tehrani HK, Haghshenas HF. Hydrated lime effect on moisture susceptibility of warm mix asphalt. Construction and Building Materials. 2012;36:165-70.

[2] Yusri MA, Meor OH. Effects of Anti-Stripping Additives on Moisture Sensitivity of Warm Porous Asphalt Mixtures. International Journal of Construction Technology Management. 2014;1(1):1-7.

[3] Gorkem C, Sengoz B. Predicting stripping and moisture induced damage of asphalt concrete prepared with polymer modified bitumen and hydrated lime. Construction and Building Materials 2009;23(6):2227-36.

[4] Usman N, Masirin MIBM, Ahmad KA, Wurochekke AA. Reinforcement of Asphalt Concrete Mixture using Recycle Polyethylene Terephthalate Fibre. Indian Journal of Science and Technology. 2016;9(December).

[5] Herráiz TR, Herráiz JIR, Domingo LM, Domingo FC. Posidonia oceanica used as a new natural fibre to enhance the performance of asphalt mixtures. Construction and Building Materials. 2016;102:601-12.

[6] Anurag K, Xiao F, Amirkhanian SN. Laboratory investigation of indirect tensile strength using roofing polyester waste fibers in hot mix asphalt. Construction and Building Materials. 2009;23(5):2035-40.

[7] Xue Y, Qian Z. Development and performance evaluation of epoxy asphalt concrete modified with mineral fiber. Construction and Building Materials 2016;102:378-83.

[8] Plasticseurope. Plastics - the Facts 2014 / 2015 An analysis of European plastics production, demand and waste data. 2015.

[9] Hoornweg D, Bhada-Tata P. What a waste: a global review of solid waste management. World Bank, Washingt DC. 2012.

[10] Panda AK, Singh RK, Mishra DK. Thermolysis of waste plastics to liquid fuel: A suitable method for plastic waste management and manufacture of value added products - A world prospective. Renew Sustain Energy Rev. 2010;14:233-48.

[11] Rahman WMNWA, Wahab AFA. Green pavement using recycled Polyethylene Terephthalate (PET) as partial fine aggregate replacement in modified asphalt. Procedia of Engineering. 2013;53:124-8.

[12] Ghasemi M, Marandi SM. Laboratory Studies of the Effect of Recycled Glass Powder Additive on the Properties of Polymer Modified Asphalt Binders. International Journal of Engineering Transaction A Basic. 2013;26(10):1183-90.

[13] Venkatachalam S, Nayak S, Labde J. Degradation and Recyclability of Poly (Ethylene Terephthalate). Polyester. 2012;75-98.

[14] AASHTO-T283. Resistance of compacted asphalt mixtures to moisture-induced damage. American Association of State Highway Transpotation Officials Washingt DC. 2007;2(25 mm):1-6.

[15] Haghshenas HF, Khodaii A, Hossain M, Gedafa DS. Stripping Potential of HMA and SMA: A Study Using Statistical Approach. Journal of Materials in Civil Engineering. 2013;27(11):1-6.

[16] Haghshenas HF, Khodaii A, Khedmati M, Tapkin S. A mathematical model for predicting stripping potential of Hot Mix Asphalt. Construction and Building Materials. 2015;75:488-95.

[17] Moghaddam TB, Karim, Soltani M, Rehan M, Baaj H. Optimization of asphalt and modifier contents for polyethylene terephthalate modified asphalt mixtures using response surface methodology. Measurement. 2015;74:159-69.

[18]Montgomery JD. Design and analysis of experiments. 6th editio. New York: Wiley \& Sons; 2006.

[19] Patrick CN, Ebere M. Optimization of Chemical Treatment Conditions for Adenia Lobata Fiber Using CCD. International Journal of Engineering Technology. 2014;4(6):23-32.

[20] Xiong R, Fang J, Xu A, Guan B, Liu Z. Laboratory investigation on the brucite fiber reinforced asphalt binder and asphalt concrete. Construction and Building Materials. 2015;83:44-52. 